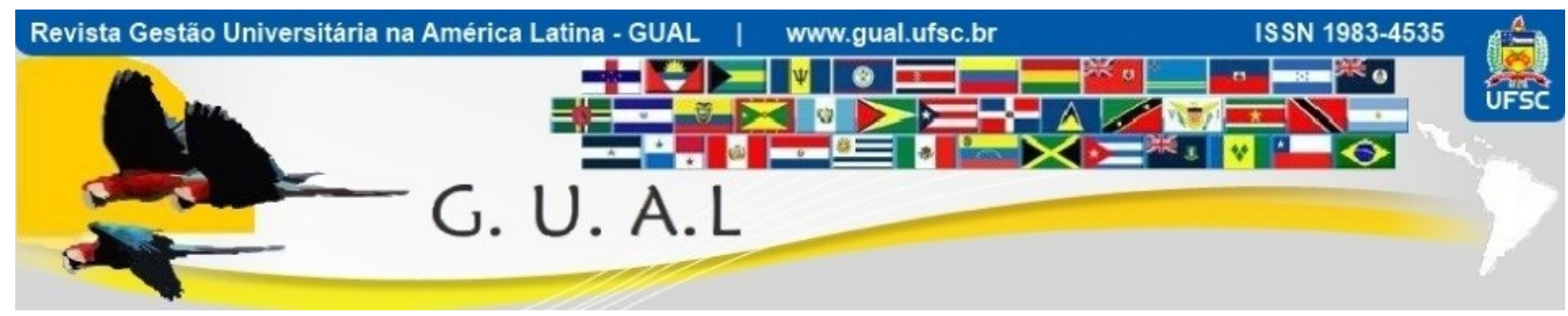

DOI: http://dx.doi.org/10.5007/1983-4535.2017v10n2p249

\title{
O GAP ENTRE AS EXPECTATIVAS DO SERVIÇO ESPERADO PELOS ALUNOS E AS EXPECTATIVAS DOS ALUNOS NA VISÃO DO CORPO DOCENTE
}

\section{THE GAP BETWEEN THE EXPECTED SERVICE BY STUDENTS AND THE STUDENT'S EXPECTATIONS IN THE VIEW OF THE FACULTY}

\author{
Sulyana Comério Margotto Borghi, Mestre \\ FUCAPE Business School \\ sulyana.margotto@gmail.com \\ Emerson Wagner Mainardes, Doutor \\ FUCAPE Business School \\ emerson@fucape.br \\ Érika Ronqueti Terra Silva, Mestre \\ FUCAPE Business School \\ ronqueti.t@gmail.com
}

Recebido em 23/novembro/2015

Aprovado em 27/janeiro/2017

Sistema de Avaliação: Double Blind Review

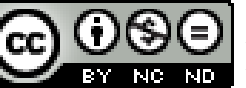

Esta obra está sob uma Licença Creative Commons Atribuição-Uso. 


\title{
RESUMO
}

As Instituições de Ensino Superior (IES) estão cada vez mais interessadas no desenvolvimento de ferramentas que possibilitem avaliar e gerenciar as expectativas dos seus discentes, com o propósito de atrá́-los e mantê-los satisfeitos. Este estudo se propôs a investigar o gap entre o que o corpo docente acredita que o aluno espera de um curso e de uma IES e as reais expectativas do aluno ingressante no ensino superior. Para tanto, foi realizada uma pesquisa quantitativa com alunos ingressantes de uma IES por meio da aplicação de um questionário. Para possibilitar a análise do gap, também foram coletadas as percepções do corpo docente da IES por meio de questionário adaptado. Os resultados da investigação demonstraram que o corpo docente acredita que o aluno espera aspectos relacionados à estrutura física, tecnologia, processos internos e recursos necessários na prestação de serviço de ensino. No entanto, o aluno espera uma colocação no mercado de trabalho e sua ascensão na carreira profissional e na vida pessoal. Concluiu-se que identificar a existência do gap possibilitará à IES ajustar seus serviços de maneira mais assertiva, podendo levar os alunos à satisfação.

Palavras-chave: Ensino superior. Expectativas dos discentes. Cinco gaps da qualidade. Gap do conhecimento.

\begin{abstract}
Higher Education Institutions (HEI) are ever more interested in the development of tools that would enable to evaluate and manage the expectations of their students, with the purpose of attracting and keeping them satisfied. This study has proposed to compare what the gap between what faculty believes the student to expect from a course from a HEI and the real expectations of the student entering higher education. For this purpose, a quantitative research was conducted with students from a HEI through the application of a questionnaire. In order to enable the gap analysis, the faculties' perceptions at the HEI were also collected through an adapted questionnaire. The results of the investigation demonstrated that the faculty believes that the student expects aspects related to the physical infrastructure, technology, internal processes and the required resources for the teaching service delivery. However, the student expects a placement in the market and their ascension in their professional and personal lives. We concluded that to identify the existence of the gap will enable the HEI to adjust its services in a more assertively manner, which can lead students to satisfaction.
\end{abstract}

Keywords: Higher education. Students' expectations. teachers' expectations. Five quality gaps. Knowledge gap. 


\section{INTRODUÇÃO}

A elevada quantidade de instituições de ensino superior (IES) e o excesso de oferta de vagas nos cursos de graduação criam a necessidade de ações estratégicas orientadas para o mercado com o propósito de atrair e reter alunos. Desse modo, as IES estão cada vez mais concentradas na melhoria da qualidade dos serviços prestados. (ABDULLAH, 2006; AKAREEM \& HOSSAIN, 2012; DUZEVIC, 2015; FAGANEL, 2010; GRAY, SWAIN \& RODWAY-DYER, 2014; GREBENNIKOV \& SHAH, 2013; GRUBER, 2014; HEADAR, ELAREF \& YACOUT, 2013; HILL, 1995; MAINARDES, ALVES \& RAPOSO, 2014; MAINARDES, RAPOSO \& ALVES, 2012; MAVONDO, TSARENKO \& GABBOTT, 2004; SARRICO \& ROSA, 2014).

No que se refere a qualidade de serviços, Parasuraman, Zeithaml \& Berry (1985) propuseram o modelo de Análise dos 5 Gaps da Qualidade (Gap Analysis), que proporciona às empresas de serviços um modelo de medida da qualidade, comparando as expectativas dos clientes com o que ele efetivamente percebe do serviço recebido. O modelo apresenta um gap externo (Gap 5), que mensura a diferença entre o serviço esperado e o serviço percebido. Os outros quatro gaps (Gaps 1-4) apontam fatores internos que explicam a falha na entrega do serviço esperado. A dimensão focalizada neste estudo envolve o Gap 1 que, neste caso, identifica a diferença entre as expectativas do serviço esperado pelos alunos ingressantes no ensino superior e as expectativas dos alunos na visão do corpo docente (MARIMUTHU \& ISMAIL, 2012).

Apesar das pesquisas realizadas, raras são as que consideram as expectativas dos alunos como objeto de pesquisa. O aprofundamento do tema é necessário para conhecê-las e, assim, gerenciá-las (ABDULLAH, 2006; DAVIES, 2002; FAGANEL, 2010; GRAY ET AL, 2014; GREBENNIKOV ET AL，2013; HEADAR ET AL，2013; JILLAPALLI \& JILLAPALLI, 2014; MAINARDES, ALVES \& RAPOSO, 2013; MAINARDES ET AL, 2014). As expectativas dependem de vários fatores: cultura, gênero, idade, tipo de universidade e modalidade de estudo, além de sofrerem mudanças ao longo do tempo (HEADAR ET AL, 2013; PARAHOO, HARVEY \& TAMIM, 2013; SANDER, STEVENSON, KING \& COATES, 2000; SARRICO ET AL，2014; WARDLEY, BÉLANGER \& LEONARD, 2013). É importante destacar que a comunicação das IES com o mercado gera expectativas nos potenciais alunos. E que as experiências e a influência de parentes e amigos criam as imagens do que os alunos irão experimentar e os resultados que 
irão alcançar por meio dos estudos (AKAREEM ET AL, 2012; DAVIES, 2002; LONG, TRICKER \& RANGECROFT, 2003; MAVONDO ET AL, 2004).

Assim, este estudo pretendeu responder a seguinte questão: qual é a diferença entre as expectativas do serviço esperado pelos alunos ingressantes no ensino superior e as expectativas deste aluno na visão do corpo docente de uma instituição? Portanto, o objetivo deste estudo foi encontrar o gap do conhecimento, que trata da diferença entre o que os provedores de serviços (neste caso, corpo docente) acham que os discentes esperam e as reais expectativas desses alunos.

Um dos motivos que justificam a realização desta pesquisa é a investigação do gap 1 no contexto do ensino superior, ao comparar as expectativas de alunos ingressantes com o que o corpo docente acredita que o aluno espera. Outra justificativa para a escolha do tema se deve ao fato de que conhecer se o corpo docente está alinhado com as expectativas dos alunos pode ser fundamental para as IES satisfazer e reter os seus alunos.

Para alcançar o objetivo da pesquisa utilizou-se o modelo dos cinco gaps da qualidade, com aprofundamento no gap 1. Para isso, foi desenvolvido um questionário de acordo com as expectativas dos alunos previamente identificadas na revisão de literatura. Além disso, foram acrescentadas variáveis para identificar o grau de expectativa geral do aluno com o curso e com a IES. Primeiramente, o questionário foi aplicado aos alunos. Posteriormente, foi adaptado e aplicado ao corpo docente. Os resultados da investigação demonstraram que o corpo docente acredita que o aluno espera aspectos relacionados à estrutura física, tecnologia, processos internos e recursos necessários na prestação de serviço de ensino. No entanto, o aluno espera uma colocação no mercado de trabalho e sua ascensão na carreira profissional e na vida pessoal. Concluiu-se que identificar a existência do gap possibilitará à IES ajustar seus serviços de maneira mais assertiva, podendo levar os alunos à satisfação.

\section{REFERENCIAL TEÓRICO}

\subsection{O MODELO DOS CINCO GAPS DA QUALIDADE}

Parasuraman et al (1985) propuseram o modelo dos 5 Gaps da Qualidade com o objetivo de identificar os problemas da qualidade no serviço e, então, aprimorá-la. O modelo proporciona às organizações um parâmetro de medida da qualidade, comparando as expectativas dos clientes com o que eles realmente percebem do serviço prestado, conforme relacionado no quadro 1. 


\begin{tabular}{c|l}
\hline $\begin{array}{c}\text { Gaps da } \\
\text { Qualidade }\end{array}$ & \multicolumn{1}{c}{ Lacunas da Qualidade } \\
\hline Gap 1 & $\begin{array}{l}\text { Compreende a diferença entre as expectativas dos clientes e as percepções dos gestores sobre essas } \\
\text { expectativas. }\end{array}$ \\
\hline Gap 2 & $\begin{array}{l}\text { Relaciona a diferença entre as percepções dos gestores sobre as expectativas dos clientes com as } \\
\text { especificações da qualidade do serviço. }\end{array}$ \\
\hline Gap 3 & Assimila as especificações da qualidade do serviço comparado com o que é fornecido ao cliente. \\
\hline Gap 4 & $\begin{array}{l}\text { Aborda a diferença entre o serviço prestado e as promessas de comunicações externas a respeito } \\
\text { desse serviço. }\end{array}$ \\
\hline Gap 5 & $\begin{array}{l}\text { Abrange a diferença entre as expectativas dos clientes e a percepção em relação ao desempenho do } \\
\text { serviço prestado expresso na forma de somatório dos outros gaps. }\end{array}$ \\
\hline
\end{tabular}

Quadro 15 Gaps da Qualidade.

Fonte: Parasuraman et al (1985).

Ao analisar os 5 gaps, é possível observar que eles podem ser mensurados separadamente. Sendo assim, a lacuna encontrada para o desenvolvimento desse estudo aponta para a utilização do gap 1 do modelo, que compreende a diferença entre as expectativas dos alunos ingressantes no ensino superior e as percepções do corpo docente sobre essas expectativas.

\subsection{GAP 1}

O gap 1 compreende a diferença entre as reais expectativas dos clientes e as percepções do provedor do serviço. No caso das IES, quando o corpo docente não tem informações adequadas sobre as expectativas dos discentes, pode ocorrer uma lacuna de percepção. Sem saber as reais expectativas do aluno, o corpo docente realizará demandas acadêmicas e não acadêmicas sem considerar o ponto de vista do aluno, podendo, dessa forma, gerar insatisfação e ampliar os índices de desistência nas IES (GREBENNIKOV ET AL, 2013; MARIMUTHU ET AL, 2012).

Ao pesquisar sobre as expectativas do aluno ao ingressar numa IES e comparar com o que o corpo docente acredita que o aluno espera, objetiva-se evidenciar a lacuna existente e, assim, propor melhorias na qualidade do ensino das IES.

\subsection{EXPECTATIVAS DOS ALUNOS}

A revisão da literatura evidencia que as IES estão preocupadas em utilizar ferramentas para medir a satisfação e a qualidade percebida pelo aluno. No entanto, apesar da importância do papel das expectativas e sua influência na avaliação do ensino superior, pouco se conhece sobre esse tema. (APPLETON-KNAPP \& KRENTLER, 2006; DAVIES, 2002; GRAY ET AL, 2014; GREBENNIKOV ET AL, 2013; MAINARDES ET AL, 2013; MAINARDES ET AL, 2014; MAVONDO ET AL, 2004; SARRICO ET AL, 2014). 


\section{O GAP ENTRE AS EXPECTATIVAS DO SERVIÇO ESPERADO PELOS ALUNOS E AS EXPECTATIVAS DOS ALUNOS NA VISÃO DO CORPO DOCENTE \\ DOI: http://dx.doi.org/10.5007/1983-4535.2017v10n2p249}

Serviços educacionais precisam ser medidos e acompanhados. Investir em qualidade nos serviços significa reduzir custos, aumentar a receita, reter clientes e atrair novos clientes. Portanto, a qualidade nos serviços deve estar ligada ao investimento realizado nos aspectos que os clientes valorizam, caso contrário as empresas desperdiçarão recursos. (ABDULLAH, 2006; DAVIES, 2002; GRAY ET AL, 2014; GREBENNIKOV ET AL, 2013; LONG, TRICKER, RANGECROFT \& GILROY, 1999; MAINARDES ET AL, 2014).

A satisfação do aluno com o curso e com a IES é resultante de uma série de variáveis, conforme relacionado no quadro 2. Portanto, compreender como as expectativas afetam a satisfação torna-se um importante papel para educadores e gestores acadêmicos. Dessa forma, poderão gerenciar corretamente as expectativas dos estudantes a cerca de um curso ou ainda atendê-las dentro das possibilidades de cada instituição (AKAREEM ET AL, 2012; ALFATTAL \& AYOUBI, 2013; APPLETON-KNAPP ET AL, 2006; DAVIES, 2002; GRAY ET AL, 2014; GREBENNIKOV ET AL, 2013; MAINARDES ET AL, 2013; MAINARDES ET AL, 2014; SARRICO ET AL, 2014).

\begin{tabular}{|c|c|c|}
\hline $\mathbf{N}^{\mathbf{0}}$ & Expectativa & Definição \\
\hline 1 & O curso possui um alto grau de exigência. & $\begin{array}{l}\text { O grau de exigência do curso está dentre as demandas mais } \\
\text { valorizadas em uma avaliação de satisfação do serviço de } \\
\text { ensino universitário (APPLETON-KNAPP ET AL, 2006; } \\
\text { MARTÍNEZ \& TOLEDO, 2013; SUARMAN, AZIZ \& } \\
\text { YASIN, 2013). }\end{array}$ \\
\hline 2 & Após o curso, conseguir um bom emprego. & $\begin{array}{l}\text { O aluno espera que as perspectivas de um bom emprego } \\
\text { sejam aprimoradas com o curso superior (DAVIES, 2002; } \\
\text { LONG ET AL, 2003; MAINARDES ET AL, 2013; } \\
\text { MARTÍNEZ ET AL, 2013). }\end{array}$ \\
\hline 3 & $\begin{array}{l}\text { Fazer novos amigos e ter vida acadêmica } \\
\text { animada. }\end{array}$ & $\begin{array}{l}\text { Os alunos esperam que a instituição de ensino forneça } \\
\text { suporte para atividades não acadêmicas e de interação social. } \\
\text { (AL-FATTAL ET AL, 2013; CRISP, PALMER, } \\
\text { TURNBULL, NETTELBECK, WARD, LECOUTEUR, } \\
\text { SARRIS, STRETAN \& SCHNEIDER, 2009; MAINARDES } \\
\text { ET AL, 2013; PARAHOO ET AL, 2013; RAVINDRAN \& } \\
\text { KALPANA, 2012). }\end{array}$ \\
\hline 4 & $\begin{array}{l}\text { Disciplinas do curso atualizadas, } \\
\text { interessantes e ligadas à realidade social e à } \\
\text { profissão. }\end{array}$ & $\begin{array}{l}\text { As IES são desafiadas a agregar valor aos seus cursos por } \\
\text { meio de disciplinas atualizadas e conectadas com a realidade } \\
\text { do mercado de trabalho, mas que também prepare o aluno } \\
\text { para pensar criticamente sobre o ambiente social que o cerca } \\
\text { (SUARMAN ET AL, 2013). }\end{array}$ \\
\hline 5 & $\begin{array}{l}\text { Apoio financeiro da IES por meio de } \\
\text { programas de bolsas e financiamentos. }\end{array}$ & $\begin{array}{l}\text { O valor da mensalidade é um atributo relevante na atração de } \\
\text { alunos. E os alunos matriculados em IES particulares } \\
\text { precisam obter recursos para o financiamento do curso } \\
\text { escolhido (DAVIES, 2002; MAINARDES ET AL, 2012). }\end{array}$ \\
\hline 6 & $\begin{array}{l}\text { Novas e ricas experiências pessoais e } \\
\text { educacionais. }\end{array}$ & $\begin{array}{l}\text { O aluno tem a expectativa de que a vida universitária será } \\
\text { rica de novas experiências e ele espera vivenciá-las (CRISP } \\
\text { ET AL, 2009; MAINARDES ET AL, 2013; RAVINDRAN } \\
\text { ET AL, 2012). }\end{array}$ \\
\hline
\end{tabular}




\section{O GAP ENTRE AS EXPECTATIVAS DO SERVIÇO ESPERADO PELOS ALUNOS E AS EXPECTATIVAS DOS ALUNOS NA VISÃO DO CORPO DOCENTE \\ DOI: http://dx.doi.org/10.5007/1983-4535.2017v10n2p249}

\begin{tabular}{l|l|}
7 & Boa estrutura física. \\
& \\
\hline
\end{tabular}

alunos (bibliotecas, serviços acadêmicos,

8 laboratórios, serviços de alimentação, entre outros).

9 Crescimento e desenvolvimento pessoal e profissional.

Professores com vontade de ajudar, ouvir,

10 responder perguntas e disponíveis para os alunos.

11 Realização de investigações científicas.

Honestidade na comunicação da IES para

12 responder às demandas dos alunos com respeito e autenticidade.

13 Processos burocráticos bem claros e definidos.

Acesso a todas as informações acadêmicas

14 e não acadêmicas do curso por meio de ferramentas online.

15 Acesso à tecnologia de última geração.

16 IES com fortes ligações com o mercado de trabalho.

17 Liberdade de pensamento e expressão.

18 Senso de camaradagem na partilha de conhecimento com professores e colegas.

Realizar trabalhos voluntários em causas

19 sociais da localidade onde a IES está inserida.

20 Após a conclusão do curso, obter rápida estabilidade financeira.

21 Ampliar as capacidades pessoais com novos conhecimentos adquiridos.

Encontrar na IES um ambiente agradável e propício ao aprendizado.
O serviço educacional possui a característica da intangibilidade, onde o aluno compra um desempenho. Por isso, o aluno frequentemente avalia a IES por causa das instalações físicas (BITNER, 1990; DAVIES, 2002; MAINARDES ET AL, 2013).

O aluno deposita expectativas de que as interações entre ele e a IES atendam às suas necessidades (MAINARDES ET AL, 2013; SAMPAIO, PERIN, SIMÕES \& KLEINOWSKI, 2012).

O aluno espera que o curso superior o ajude a obter instrução para progredir na carreira ou ainda, alcançar realizações pessoais (AL-FATTAL ET AL, 2013; MAINARDES ET AL, 2013; SURMAN, AZIZ \& YASIN, 2013).

Os alunos esperam interação com os professores, e que a disponibilidade e o acesso imediato contribuirão com o seu sucesso (AKAREEM ET AL, 2012; APPLETON-KNAPP ET AL, 2006; CRISP ET AL, 2009; DAVIES, 2002; MARIMUTHU ET AL, 2012).

O aluno espera participar de pesquisas científicas (MAINARDES ET AL, 2012).

$\mathrm{O}$ aluno espera que a relação com a IES seja honesta e autêntica. Além disso, observa se as demandas são atendidas ou não e no tempo hábil. (DAVIES, 2002; MARIMUTHU ET AL, 2012; SAMPAIO ET AL, 2012).

O aluno espera que os aspectos burocráticos da relação aluno e IES sejam claros, bem definidos e precisos (ABDULLAH, 2006; DAVIES, 2002; MAINARDES ET AL, 2013).

Expectativa relacionada à disponibilidade, acessibilidade, facilidade de contato e conveniência do aluno, calcados em bases tecnológicas (DAVIES, 2002; HEADAR ET AL, 2013; MARIMUTHU ET AL, 2012).

O crescimento da tecnologia aumenta o nível de expectativa do aluno para o acesso à tecnologia de ponta (laboratórios, periódicos, rede, etc) (DAVIES, 2002; MARIMUTHU ET AL, 2012).

Expectativa de que a IES será um trampolim para o mercado de trabalho (DAVIES, 2002; MAINARDES ET AL, 2012; MARIMUTHU ET AL, 2012; MARTÍNEZ ET AL, 2013).

$\mathrm{O}$ aluno espera ter mais liberdade e independência e se ajustar ao meio acadêmico, equilibrando exigências do curso e liberdade de atuação (CRISP ET AL, 2009; KRIEG, 2013).

Os alunos esperam a partilha de conhecimento entre professores e colegas e o senso de camaradagem nas aulas (APPLETON-KNAPP ET AL, 2006).

O aluno espera participar de ações que envolvam trabalho voluntário social na IES escolhida (MAINARDES ET AL, 2012).

O aluno espera que, após a conclusão do curso superior, ele irá experimentar rápida estabilidade financeira (CRISP ET AL, 2009; DAVIES, 2002; MARTÍNEZ ET AL, 2013).

Os alunos esperam que o curso superior contribua com a ampliação da sua capacidade de buscar seus objetivos de carreira e vida (SUARMAN ET AL, 2013).

Equilibrar estudo e trabalho exige do aluno equilíbrio e ele espera que a IES forneça um ambiente de aprendizagem flexível e interessante (AKAREEM ET AL, 2012; LONG ET AL, 1999; MAINARDES ET AL, 2013). 


\begin{tabular}{|c|c|c|}
\hline 23 & $\begin{array}{l}\text { IES propicie eventos relacionados aos } \\
\text { cursos. }\end{array}$ & $\begin{array}{l}\text { O aluno alimenta expectativas de que participará do processo } \\
\text { de construção do conhecimento, dentre eles, em eventos } \\
\text { relacionados ao curso dele (MARTINEZ, BERBÉN, ARIAS } \\
\text { \& JUSTICIA, 2007; SANDER ET AL, 2000; STEVENSON } \\
\text { \& SANDER, 1998). }\end{array}$ \\
\hline 24 & $\begin{array}{l}\text { Após a conclusão do curso, o aluno } \\
\text { continuará seus estudos em uma pós- } \\
\text { graduação. }\end{array}$ & $\begin{array}{l}\text { A educação continuada é considerada um atributo importante } \\
\text { na transição da IES com o mercado (SAMPAIO ET AL, } \\
\text { 2012). }\end{array}$ \\
\hline 25 & $\begin{array}{l}\text { O professor utilizará todos os recursos } \\
\text { disponíveis para o planejamento do curso e } \\
\text { execução das aulas. }\end{array}$ & $\begin{array}{l}\text { Os alunos confiam que o professor se envolverá com o } \\
\text { processo de ensino e aprendizagem e esperam que o } \\
\text { professor utilize todos os recursos disponíveis, tanto no } \\
\text { planejamento do curso, quanto na execução das aulas } \\
\text { (EMANUEL \& ADAMS, 2006; SAMPAIO ET AL, 2012). }\end{array}$ \\
\hline 26 & $\begin{array}{l}\text { Negociação dos métodos de ensino, } \\
\text { aprendizagem e avaliação entre alunos e } \\
\text { professores. }\end{array}$ & $\begin{array}{l}\text { Os alunos acreditam que novas formas de ensino e diferentes } \\
\text { recursos nas aulas serão utilizados, considerando suas } \\
\text { preferências de ensino e aprendizagem (APPLETON- } \\
\text { KNAPP ET AL, 2006; CRISP ET AL, 2009; DAVIES, } \\
\text { 2002; MARTINEZ ET AL, 2007; MAVONDO ET AL, } \\
\text { 2004; SANDER ET AL, 2000). }\end{array}$ \\
\hline 27 & Adequado tamanho das turmas. & $\begin{array}{l}\text { O tamanho das turmas é um item importante na concepção } \\
\text { do aluno e pode afetar futuras percepções de satisfação e } \\
\text { desempenho da IES (ABDULLAH, 2006; APPLETON- } \\
\text { KNAPP ET AL, 2006). }\end{array}$ \\
\hline 28 & $\begin{array}{l}\text { Comunicação precisa sobre cursos, } \\
\text { procedimentos de avaliação e processo de } \\
\text { reclamações. }\end{array}$ & $\begin{array}{l}\text { O aluno constrói expectativas de que a comunicação da IES } \\
\text { com os alunos será de forma precisa e responsável, por meio } \\
\text { de um feedback completo e rápido (DAVIES, 2002; } \\
\text { MARIMUTHU ET AL, 2012; SAMPAIO ET AL, 2012). }\end{array}$ \\
\hline 29 & $\begin{array}{l}\text { Cursos com mais aulas práticas do que } \\
\text { teóricas. }\end{array}$ & $\begin{array}{l}\text { Os alunos esperam que as disciplinas teóricas da grade de } \\
\text { ensino estarão integradas com a prática e que, desse modo, } \\
\text { serão preparados para a rotina de trabalho. (MAINARDES, } \\
\text { ET AL, 2013; SUARMAN ET AL 2013). }\end{array}$ \\
\hline 30 & Aulas agradáveis e interessantes. & $\begin{array}{l}\text { Uma grade curricular relevante para os alunos e que amplie } \\
\text { sua empregabilidade são expectativas latentes. Aulas } \\
\text { agradáveis e interessantes são expectativas que o aluno } \\
\text { alimenta em função de estar ingressando em uma IES com } \\
\text { professores graduados e experientes (CRISP ET AL, 2009; } \\
\text { MAINARDES ET AL, 2013; SUARMAN ET AL, 2013). }\end{array}$ \\
\hline
\end{tabular}

Quadro 2 Expectativas dos alunos.

Fonte: Elaboração própria.

\section{METODOLOGIA DE PESQUISA}

Para atingir o objetivo da pesquisa, o método escolhido foi quantitativo e descritivo. A pesquisa foi aplicada em uma IES sediada no Estado do Espírito Santo/Brasil. A escolha pela IES se deve ao fato de que a mesma vem enfrentando uma competição acirrada com outras IES da região, tanto na modalidade de aulas presenciais, quanto de ensino a distância.

Assim, duas populações alvo (alunos e professores) foram selecionadas para atender o objetivo da pesquisa. A primeira foi composta por uma amostra de 237 alunos ingressantes no ensino superior, sendo a pesquisa aplicada na primeira semana de aula, mas precisamente no 
dia 05.02.2014. A outra população em estudo foi composta pelo corpo docente da IES pesquisada, cujas respostas foram obtidas junto a 71 professores.

Para a aplicação da pesquisa, foi elaborado um questionário, com base nas expectativas dos alunos, previamente identificadas na revisão da literatura (quadro 2). Além disso, foram acrescentadas variáveis para identificar o grau de expectativa geral do aluno com o curso e com a IES, totalizando 32 questões. As questões de classificação do respondente abordaram gênero, idade e curso. O questionário aplicado para o corpo docente da IES foi adaptado do questionário aplicado para os alunos. $\mathrm{O}$ intuito foi encontrar o gap 1, portanto, os dados coletados do corpo docente foram utilizados para identificar a lacuna existente entre as percepções de alunos e professores.

Após a definição de conteúdo do instrumento de pesquisa, foi escolhida a escala de Likert de 5 pontos, variando de "discordo totalmente" a "concordo totalmente". Dessa forma, foi possível identificar o grau de discordância ou concordância dos respondentes para cada uma das questões propostas no estudo. Em seguida, em virtude do problema de pesquisa, optou-se pela análise de regressão linear múltipla para identificar as diferenças de percepção entre alunos e docentes em relação às expectativas dos alunos ingressantes.

\section{ANÁLISE DOS DADOS}

A análise foi subdividida em etapas: caracterização da amostra dos discentes e do corpo docente, estatística descritiva da amostra dos discentes e do corpo docente, e por fim, regressão linear múltipla para análise das variáveis dependentes (expectativa quanto ao curso e expectativa quanto à IES) da amostra dos discentes e do corpo docente.

\subsection{CARACTERIZAÇÃO DA AMOSTRA DOS DISCENTES E DO CORPO DOCENTE}

A amostra representada pelos 237 alunos ingressantes indicou que: 61,48\% dos entrevistados pertencem ao gênero feminino, 74,26\% possuem entre 16 e 21 anos e 35,03\% dos respondentes foram alunos ingressantes no curso de Direito. De acordo com a gestão da IES, essa amostra de alunos pode ser considerada representativa para a IES, tendo em vista que representa o típico aluno ingressante da IES pesquisada. Com relação ao corpo docente, em um total de 71 professores participantes da pesquisa, observou-se um equilíbrio entre o gênero masculino (50,70\%) e o gênero feminino (49,30\%). Além disso, os resultados indicam que dos professores participantes do estudo, a maioria leciona para os cursos de 
Administração, Direito e Pedagogia (56,34\%). Neste caso, a amostra pesquisada também pode ser considerada representativa da população de docentes da IES.

\subsection{ESTATÍSTICA DESCRITIVA DA AMOSTRA DOS DISCENTES E DO CORPO DOCENTE}

Primeiramente, com o objetivo de observar à média e o desvio padrão das variáveis, optou-se por calcular as estatísticas descritivas de cada variável na amostra dos discentes e, em seguida, na amostra do corpo docente. (HAIR JR., CELSI, MONEY, SAMOUEL \& PAGE, 2011).

\subsubsection{Estatística Descritiva da Amostra dos Discentes}

De acordo com os resultados, a maior média foi obtida na variável $21(\mathrm{M}=4,79)$, que considerou a expectativa de ampliar as capacidades pessoais com novos conhecimentos adquiridos. Posteriormente, observou-se um destaque para a variável $22(\mathrm{M}=4,78)$, que abordou sobre encontrar na IES um ambiente agradável e propício ao aprendizado. A terceira maior média foi obtida da variável $9(\mathrm{M}=4,78)$, que questionou sobre o crescimento e o desenvolvimento pessoal e profissional. É importante destacar que as três variáveis com maior média envolvem os resultados esperados da prestação de serviço de ensino superior, que consequentemente envolve a construção de uma carreira e a busca por realizações pessoais. Akareem et al (2012) afirmaram que os alunos esperam da IES o compromisso de repasse de conhecimento cognitivo e a ampliação de suas competências, o que reforça os resultados desta pesquisa.

A menor média foi encontrada na variável $11(\mathrm{M}=3,80)$ que considerou a realização de pesquisas científicas. Essa média possivelmente deve-se ao fato de que a IES pesquisada não insere o aluno em programas de pesquisa, portanto, não gera tais expectativas. De acordo com Davis (2002), a comunicação da IES somada às experiências dos alunos é que constrói a imagem do que o aluno vai experimentar e este resultado se mostra coerente com o que a IES sustenta. Apesar disso, observou-se que a maior parte dos alunos espera participar de pesquisas científicas, visto que o resultado da média foi próximo de $4,(M=3,80)$.

A segunda menor média foi encontrada na variável $15(\mathrm{M}=3,92)$, que analisou o acesso à tecnologia de última geração. Nesse caso, os resultados evidenciam, possivelmente, os laboratórios básicos da IES e a falta de acesso à base de periódicos científicos online. A terceira menor média foi atribuída à variável $5(\mathrm{M}=3,94)$, que mencionou o apoio financeiro 
da IES por meio de programas de bolsas e financiamentos. Essa variável mostra que o aluno demonstra que a expectativa de conseguir se beneficiar de um programa de bolsa ou financiamento é menor do que outras expectativas. Complementarmente, a literatura evidencia que o valor da mensalidade é um importante atributo de atratividade para as IES (DAVIES, 2002; MAINARDES ET AL, 2012).

A maior falta de consenso foi encontrada na variável $5(\mathrm{DP}=1,24)$, que representou o apoio financeiro da IES por meio de bolsas e financiamentos. Isto significa que somente parte dos alunos espera apoio financeiro da IES. O segundo maior desvio padrão foi encontrado na variável 15 ( $\mathrm{DP}=0,94)$, que considerou o acesso à tecnologia de última geração. $\mathrm{O}$ crescimento da tecnologia aumentou o nível de expectativa do aluno (MARIMUTHU ET AL, 2012), mas a falta de consenso demonstrada indica que os alunos pesquisados pensam de modo diferente. $\mathrm{O}$ terceiro maior desvio padrão foi encontrado na variável $20(\mathrm{DP}=0,88)$, que mencionou que após o curso o aluno obterá rápida estabilidade financeira. Nesse quesito, a falta de consenso também foi demonstrada. Possivelmente, quando os alunos avaliaram essas três variáveis, parte deles resgatou experiências vividas ou relatadas que demonstraram alguma insatisfação (DAVIES, 2002).

O menor desvio padrão foi encontrado na variável $22(\mathrm{DP}=0,51)$, que considerou a relevância de encontrar na IES um ambiente agradável e propício ao aprendizado. Esse resultado associado à média alta encontrada na mesma variável reforça a importância das condições que o aluno espera encontrar em uma IES (AKAREEM ET AL, 2012; LONG ET AL, 1999; MAINARDES ET AL, 2013).

O segundo menor desvio padrão foi encontrado na variável $9(\mathrm{DP}=0,52)$, que está relacionada ao crescimento e desenvolvimento pessoal e profissional, representando que as respostas dos alunos nessa variável são mais consensuais. É importante destacar que nesse quesito também foi identificado maior média entre os alunos pesquisados. Seguidamente, observou-se o baixo desvio padrão na variável 21 ( $\mathrm{DP}=0,51)$, que tratou de ampliar capacidades pessoais com novos conhecimentos adquiridos. Essa variável também obteve média alta, demonstrando que o aluno realmente espera que o curso superior amplie suas competências pessoais. A IES atenta a essas demandas procura adequar seus programas educacionais às necessidades e expectativas dos alunos (AL-FATTAL ET AL, 2013; DUZEVIC, 2015; GRAY ET AL, 2014; GREBENNIKOV ET AL, 2013; MAINARDES ET 
AL, 2013; MAINARDES ET AL, 2014; SARRICO ET AL, 2014; SURMAN, AZIZ \& YASIN, 2013).

\subsubsection{Estatística Descritiva da Amostra do Corpo Docente}

A maior média encontrada foi obtida na variável $30(\mathrm{M}=4,90)$, que considerou que o docente acha que o aluno espera aulas agradáveis e interessantes. A literatura mostra que o professor sabe que a prestação de serviço fornecida ao aluno pela IES é por meio das aulas (CRISP ET AL, 2009), e os resultados indicam, na visão do professor, que esta parece ser uma importante expectativa do aluno. A segunda maior média foi identificada na variável 8 $(\mathrm{M}=4,83)$, que mencionou sobre os serviços da IES estarem adequados às necessidades dos alunos. Para o professor, toda a estrutura deverá estar adequada, acessível e pronta para a sua utilização, pois ele acredita que é isso que o aluno espera. (BITNER, 1990; DAVIES, 2002; GRAY ET AL, 2014; MAINARDES ET AL, 2013; SARRICO ET AL, 2014). A terceira maior média foi encontrada na variável $10(\mathrm{M}=4,80)$, que abordou sobre professores com vontade de ajudar, ouvir, responder perguntas e disponíveis para os alunos. Nesse caso, o docente assume que o discente espera um bom processo de comunicação e interação entre aluno e professor. (AKAREEM ET AL, 2012; APPLETON-KNAPP ET AL, 2006; CRISP ET AL, 2009; DAVIES, 2002; GRAY ET AL, 2014; MARIMUTHU ET AL, 2012).

A menor média encontrada foi na variável $19(\mathrm{M}=2,87)$, sobre o aluno realizar trabalhos voluntários. Ficou evidente que o professor não acredita que o aluno possua essa expectativa, pois a maior parte deles discorda dessa afirmação. Mainardes et al (2012) afirmaram que a expectativa de realizar trabalhos voluntários é uma demanda secundária dos alunos, mas que também pode ser considerada relevante.

A segunda menor média encontrada foi na variável $11(\mathrm{M}=3,05)$, que pesquisou a realização de investigações científicas. O professor acredita que o aluno não espera por tal atividade acadêmica. No entanto, essa expectativa foi identificada na pesquisa de Mainardes et al (2012). A terceira menor média foi identificada na variável $1(\mathrm{M}=3,54)$, que considerou o alto grau de exigência do curso. Nesse caso, o professor não acredita que o aluno espera alto grau de exigência do curso. Dessa forma, parece que o professor pensa que o aluno deseja um futuro interessante no tocante à carreira e sucesso na vida, mas que não quer se esforçar no presente para alcançar tais objetivos. 
Dentre os desvios padrão encontrados, o maior deles está na variável $19(\mathrm{DP}=1,22)$, que trata da realização de trabalhos voluntários pelo aluno. Essa variável apresenta a maior dispersão, mas também a menor média. Esse resultado demonstra falta de consenso do corpo docente, o que leva a considerar que parte dos professores não acredita que o aluno possua a expectativa de atuar solidariamente em causas sociais.

O segundo e terceiro maiores desvios padrão foram identificados nas variáveis 11 (DP $=1,21)$, realização de investigações científicas e $1(\mathrm{DP}=1,11)$, curso com alto grau de exigência, que demonstram a falta de consenso entre os professores quando consideradas essas variáveis. Vale salientar que a literatura mostra que as IES estão procurando adequar seus programas de ensino para atender as demandas de alunos mais ativos e críticos, diferente dos alunos passivos do passado (MIZIKACI, 2006).

Os menores desvios padrão foram encontrados nas variáveis $30(\mathrm{DP}=0,30)$, que considerou aulas agradáveis e interessantes, seguido da variável 8 ( DP =0,48), que mencionou sobre os serviços da IES adequados às necessidades dos alunos e da variável 7 $(\mathrm{DP}=0,53)$, que pesquisou sobre a boa estrutura física. Tais resultados apontam que os professores acreditam que os alunos realmente esperam adequada prestação de serviço da IES. Vale relembrar que as médias dessas mesmas variáveis estão entre as maiores médias encontradas na estatística descritiva dos professores pesquisados. A literatura vem mostrando uma nova abordagem na avaliação da qualidade da IES, que passa por avaliar e investir nos aspectos não acadêmicos da experiência educacional (ABDULLAH, 2006; DUZEVIC, 2015; GRAY ET AL, 2014; GREBENNIKOV ET AL, 2013; SARRICO ET AL, 2014).

\subsection{REGRESSÃO LINEAR MÚLTIPLA}

Inicialmente, a regressão linear múltipla foi realizada para analisar a percepção dos discentes e do corpo docente com relação à expectativa do aluno quanto ao curso. Seguidamente, também na percepção dos discentes e do corpo docente, o objetivo da regressão foi analisar a expectativa do aluno quanto à IES. Com isso, foi possível evidenciar o gap 1.

\subsubsection{Regressões para Análise da Variável Dependente: Expectativa quanto ao Curso}

Para identificar o gap 1 entre as expectativas do aluno ao ingressar em um curso superior e o que o corpo docente acha que o aluno espera, foram realizadas duas regressões 
lineares múltiplas entre as 30 variáveis independentes e a variável dependente (expectativa quanto ao curso). Os resultados das expectativas dos alunos estão demonstrados nas tabelas 1 e 2 .

Tabela 1 Modelo obtido na Regressão Linear Múltipla para os Discentes.

\begin{tabular}{|c|c|c|c|c|c|c|c|c|c|c|}
\hline \multicolumn{11}{|c|}{ Modelo Resumido } \\
\hline \multirow[b]{2}{*}{ Modelo } & \multirow[b]{2}{*}{$\mathrm{R}$} & \multirow[b]{2}{*}{$\mathrm{R}^{2}$} & \multirow[b]{2}{*}{$\begin{array}{c}\mathrm{R}^{2} \\
\text { Ajustado }\end{array}$} & \multirow{2}{*}{$\begin{array}{c}\text { Erro Padrão } \\
\text { da } \\
\text { Estimativa }\end{array}$} & \multicolumn{5}{|c|}{ Alterações Estatísticas } & \multirow[b]{2}{*}{$\begin{array}{l}\text { Durbin- } \\
\text { Watson }\end{array}$} \\
\hline & & & & & $\begin{array}{c}\text { Variação do } \\
\mathrm{R}^{2}\end{array}$ & $\begin{array}{c}\text { Alteração } \\
\text { F }\end{array}$ & \begin{tabular}{|c|} 
ddf \\
1
\end{tabular} & ddf2 & $\begin{array}{c}\text { Alterações } \\
\text { Sig. F }\end{array}$ & \\
\hline 5 & ,507 & ,257 & ,241 &, 55935 &, 013 & 4,008 & 1 & 231 &, 046 & 2,075 \\
\hline
\end{tabular}

a. Preditores: (Constante), Aulas Agradáveis e Interessantes, Ampliar as capacidades pessoais com novos conhecimentos adquiridos, Curso com alto grau de exigência, Adequado tamanho das turmas, Crescimento e desenvolvimento pessoal e profissional.

b. Variável Dependente: Expectativa quanto ao curso.

Método de estimação: Stepwise

Testes de validez:

ANOVA: significativo

Teste de Aleatoriedade: Suporta a hipótese de aleatoriedade

Teste de Aderência Kolmogorov-Smirnov: Suporta hipótese de aderência a distribuição normal

Teste de Homocedasticidade: Suporta a hipótese de homocedasticidade

Fonte: Dados da Pesquisa.

Tabela 2 Coeficientes estimados da variável dependente (Expectativa quanto ao curso) para os Discentes.

\begin{tabular}{|c|c|c|c|c|c|c|c|c|c|c|c|c|c|}
\hline \multicolumn{14}{|c|}{ Coeficientes $^{\mathrm{a}}$} \\
\hline & \multirow{2}{*}{ Modelo } & \multicolumn{2}{|c|}{$\begin{array}{l}\text { Coeficient } \\
\text { es não } \\
\text { padroniza } \\
\text { dos }\end{array}$} & \multirow{2}{*}{$\begin{array}{c}\text { Coeficient } \\
\text { es } \\
\text { Padroniza } \\
\text { dos }\end{array}$} & \multirow[t]{2}{*}{$\mathrm{tt}$} & \multirow{2}{*}{$\begin{array}{l}\text { SSi } \\
\text { g. }\end{array}$} & \multicolumn{2}{|c|}{$\begin{array}{c}95,0 \% \\
\text { Intervalo de } \\
\text { Confiança para } \\
\text { B }\end{array}$} & \multicolumn{3}{|c|}{ Correlação } & \multicolumn{2}{|c|}{$\begin{array}{l}\text { Estatística de } \\
\text { Colinearidade }\end{array}$} \\
\hline & & B & $\begin{array}{c}\text { Erro } \\
\text { Padr } \\
\text { ão }\end{array}$ & & & & $\begin{array}{l}\text { Limite } \\
\text { Inferio } \\
\quad r\end{array}$ & $\begin{array}{l}\text { Limite } \\
\text { Superi } \\
\text { or }\end{array}$ & $\begin{array}{c}\text { Orde } \\
\mathrm{m} \\
\text { Zero }\end{array}$ & $\begin{array}{c}\text { Parci } \\
\text { al }\end{array}$ & $\begin{array}{c}\text { Semipar } \\
\text { cial }\end{array}$ & $\begin{array}{c}\text { Tolerân } \\
\text { cia }\end{array}$ & VIF \\
\hline & (Constante) & $\begin{array}{c}, 77 \\
8\end{array}$ & , 428 & & $\begin{array}{c}1,81 \\
8\end{array}$ & $\begin{array}{c}, 07 \\
0\end{array}$ &,- 065 & 1,621 & & & & & \\
\hline & $\begin{array}{c}\text { Aulas } \\
\text { agradáveis e } \\
\text { interessante } \\
\text { s }\end{array}$ & $\begin{array}{c}, 21 \\
5\end{array}$ & ,071 & 197 & $\begin{array}{c}3,04 \\
3\end{array}$ & $\begin{array}{c}, 00 \\
3\end{array}$ & ,076 & ,354 & ,374 & 196 & , 173 & 769 & $\begin{array}{c}1,30 \\
1\end{array}$ \\
\hline 5 & $\begin{array}{l}\text { Ampliar as } \\
\text { capacidades } \\
\text { pessoais } \\
\text { com novos } \\
\text { conhecimen } \\
\text { tos } \\
\text { adquiridos }\end{array}$ & $\begin{array}{c}, 21 \\
2\end{array}$ & , 080 & ,176 & $\begin{array}{c}2,63 \\
7\end{array}$ & $\begin{array}{c}00 \\
9\end{array}$ & ,054 & ,371 & ,372 & ,171 & , 150 & ,722 & $\begin{array}{c}1,38 \\
5\end{array}$ \\
\hline & $\begin{array}{l}\text { Curso com } \\
\text { alto grau de } \\
\text { exigência }\end{array}$ & $\begin{array}{c}, 10 \\
0\end{array}$ & ,043 & 135 & $\begin{array}{c}2,30 \\
7\end{array}$ & $\begin{array}{c}, 02 \\
2\end{array}$ & ,015 & , 186 & 239 & , 150 & ,131 & ,936 & $\begin{array}{c}1,06 \\
9\end{array}$ \\
\hline & $\begin{array}{l}\text { Adequado } \\
\text { tamanho } \\
\text { das turmas }\end{array}$ & $\begin{array}{c}, 10 \\
6\end{array}$ & , 048 & ,136 & $\begin{array}{c}2,17 \\
6\end{array}$ & $\begin{array}{c}, 03 \\
1\end{array}$ & , 010 & ,201 & ,306 & , 142 & , 123 & ,826 & $\begin{array}{c}1,21 \\
1\end{array}$ \\
\hline
\end{tabular}




\begin{tabular}{|c|c|c|c|c|c|c|c|c|c|c|c|c|}
\hline $\begin{array}{l}\text { Cresciment } \\
\text { o e } \\
\text { desenvolvi } \\
\text { mento } \\
\text { pessoal e } \\
\text { profissional }\end{array}$ & $\begin{array}{c}, 16 \\
1\end{array}$ & ,080 & ,131 & $\begin{array}{c}2,00 \\
2\end{array}$ & $\begin{array}{c}, 04 \\
6\end{array}$ & ,003, & ,319 & 334, & 131 & ,114 & ,753 & $\begin{array}{c}1,32 \\
7\end{array}$ \\
\hline
\end{tabular}

Fonte: Dados da Pesquisa.

Após analisar os dados da tabela 1, verificou-se que o modelo possui um $\mathrm{R}^{2}$ ajustado de 0,241 , ou seja, $24,10 \%$ da variação da variável dependente do estudo, que trata da expectativa do aluno com relação ao curso, pode ser explicada pelo modelo de regressão especificado.

Por meio da tabela 2, foi possível observar que as variáveis aulas agradáveis e interessantes, ampliar as capacidades pessoais com novos conhecimentos adquiridos, curso com alto grau de exigência, adequado tamanho das turmas, crescimento e desenvolvimento pessoal e profissional, foram significativas na associação com a variável dependente (Expectativa quanto ao curso). Isto significa que as cinco variáveis afetam positivamente a expectativa do aluno com relação ao curso.

As Tabelas 3 e 4 mostram os resultados obtidos junto ao corpo docente. Após analisar os dados da tabela 3, verificou-se que o modelo possui um $\mathrm{R}^{2}$ ajustado de 0,405 , ou seja, $40,50 \%$ da variação da variável dependente (Expectativa quanto ao curso na visão do corpo docente) pode ser explicada pelo modelo de regressão apresentado.

Tabela 3 Modelo obtido na Regressão Linear Múltipla para o Corpo Docente.

\begin{tabular}{|c|c|c|c|c|c|c|c|c|c|c|}
\hline \multicolumn{11}{|c|}{ Modelo Resumido } \\
\hline \multirow[b]{2}{*}{ Modelo } & \multirow[b]{2}{*}{$\mathrm{R}$} & \multirow[b]{2}{*}{$\mathrm{R}^{2}$} & \multirow{2}{*}{$\begin{array}{c}\mathrm{R}^{2} \\
\text { Ajustado }\end{array}$} & \multirow{2}{*}{$\begin{array}{l}\text { Erro Padrão } \\
\text { da } \\
\text { Estimativa }\end{array}$} & \multicolumn{5}{|c|}{ Alterações Estatísticas } & \multirow{2}{*}{$\begin{array}{l}\text { Durbin- } \\
\text { Watson }\end{array}$} \\
\hline & & & & & $\begin{array}{c}\text { Variação do } \\
\mathrm{R}^{2}\end{array}$ & $\begin{array}{c}\text { Alteração } \\
\text { F }\end{array}$ & $\begin{array}{c}\mathrm{ddf} \\
1\end{array}$ & ddf2 & $\begin{array}{l}\text { Alterações } \\
\text { Sig. F }\end{array}$ & \\
\hline 5 & 669 & ,447 & ,405 & ,52413 & ,062 & 7,285 & 1 & 65 & ,009 & 1,709 \\
\hline \multicolumn{11}{|c|}{$\begin{array}{l}\text { a. Preditores: (Constante), Crescimento e desenvolvimento pessoal e profissional, Após a conclusão do curso, } \\
\text { obter rápida estabilidade financeira, Acesso à tecnologia de última geração, Boa estrutura física, O professor } \\
\text { utilizará todos os recursos disponíveis para o planejamento do curso e execução das aulas. }\end{array}$} \\
\hline
\end{tabular}

Método de estimação: Stepwise

Testes de validez:

ANOVA: significativo

Teste de Aleatoriedade: Suporta a hipótese de aleatoriedade

Teste de Aderência Kolmogorov-Smirnov: Suporta hipótese de aderência a distribuição normal

Teste de Homocedasticidade: Suporta a hipótese de homocedasticidade

Fonte: Dados da Pesquisa. 
Tabela 4 Coeficientes estimados da variável dependente (Expectativa quanto ao curso) para o Corpo Docente.

\begin{tabular}{|c|c|c|c|c|c|c|c|c|c|c|c|c|c|}
\hline & \multicolumn{13}{|c|}{ Coeficientes $^{\mathrm{a}}$} \\
\hline & \multirow{2}{*}{ Modelo } & \multicolumn{2}{|c|}{$\begin{array}{c}\text { Coeficiente } \\
\text { s não } \\
\text { padronizado } \\
\text { s }\end{array}$} & \multirow{2}{*}{$\begin{array}{c}\text { Coeficient } \\
\text { es } \\
\text { Padroniza } \\
\text { dos }\end{array}$} & \multirow{2}{*}{$\mathrm{tt}$} & \multirow{2}{*}{$\begin{array}{c}\mathrm{SSi} \\
\mathrm{g} .\end{array}$} & \multicolumn{2}{|c|}{$\begin{array}{c}95,0 \% \\
\text { Intervalo de } \\
\text { Confiança } \\
\text { para B }\end{array}$} & \multicolumn{3}{|c|}{ Correlação } & \multicolumn{2}{|c|}{$\begin{array}{l}\text { Estatística de } \\
\text { Colinearidade }\end{array}$} \\
\hline & & B & $\begin{array}{l}\text { Erro } \\
\text { Padr } \\
\text { ão }\end{array}$ & & & & $\begin{array}{l}\text { Limit } \\
\mathrm{e} \\
\text { Inferi } \\
\text { or }\end{array}$ & $\begin{array}{c}\text { Limite } \\
\text { Superi } \\
\text { or }\end{array}$ & $\begin{array}{l}\text { Orde } \\
\mathrm{m} \\
\text { Zero }\end{array}$ & $\begin{array}{c}\text { Parci } \\
\text { al }\end{array}$ & $\begin{array}{l}\text { Semipar } \\
\text { cial }\end{array}$ & $\begin{array}{l}\text { Tolerân } \\
\text { cia }\end{array}$ & VIF \\
\hline & (Constante) & $\begin{array}{c}2,45 \\
3\end{array}$ &, 821 & & $\begin{array}{c}2,98 \\
7\end{array}$ & \begin{tabular}{|c|}
, 00 \\
4
\end{tabular} &, 813 & 4,093 & & & & & \\
\hline & $\begin{array}{c}\text { Cresciment } \\
\text { o e } \\
\text { desenvolvi } \\
\text { mento } \\
\text { pessoal e } \\
\text { profissional }\end{array}$ & ,416 & 100 & ,390 & $\begin{array}{c}4,17 \\
1\end{array}$ & $\begin{array}{c}, 00 \\
0\end{array}$ & ,217 & 615, & ,443 & 460 & 385, & 970, & $\begin{array}{c}1,03 \\
1\end{array}$ \\
\hline & $\begin{array}{c}\text { Após a } \\
\text { conclusão } \\
\text { do curso, } \\
\text { obter rápida } \\
\text { estabilidade } \\
\text { financeira }\end{array}$ & ,323 & ,084 & ,378 & $\begin{array}{c}3,86 \\
4\end{array}$ & $\begin{array}{c}, 00 \\
0\end{array}$ & ,156 & ,489 & ,343 & 432 & 356, & 888, & $\begin{array}{c}1,12 \\
6\end{array}$ \\
\hline 5 & $\begin{array}{c}\text { Acesso à } \\
\text { tecnologia } \\
\text { de última } \\
\text { geração }\end{array}$ &,- 253 & 0,77 &,- 322 & $\begin{array}{c}3,30 \\
5\end{array}$ & $\begin{array}{c}, 00 \\
2\end{array}$ &,- 406 &,- 100 &,- 202 & $\mid-, 379$ &,- 305 & 896, & $\begin{array}{c}1,11 \\
5\end{array}$ \\
\hline & $\begin{array}{c}\text { Boa } \\
\text { estrutura } \\
\text { física }\end{array}$ &,- 381 & ,125 &,- 296 & $\begin{array}{c}- \\
3,04 \\
2\end{array}$ & $\begin{array}{c}, 00 \\
3\end{array}$ & -632 &,- 131 &,- 230 &,- 353 &,- 280 & 899, & $\begin{array}{c}1,11 \\
2\end{array}$ \\
\hline & $\begin{array}{l}\text { O professor } \\
\text { utilizará } \\
\text { todos os } \\
\text { recursos } \\
\text { disponíveis } \\
\text { para o } \\
\text { planejament } \\
\text { o do curso e } \\
\text { execução } \\
\text { das aulas }\end{array}$ & 225 & ,083 & ,282 & $\begin{array}{c}2,69 \\
9\end{array}$ & $\begin{array}{c}, 00 \\
9\end{array}$ &, 059 & ,392 & ,041 & ,317 & ,249 & ,777 & $\begin{array}{c}1,28 \\
6\end{array}$ \\
\hline
\end{tabular}

Fonte: Dados da Pesquisa.

Por meio da tabela 4, observou-se que as variáveis crescimento e desenvolvimento pessoal e profissional, após a conclusão do curso, obter rápida estabilidade financeira, acesso a tecnologias de última geração, boa estrutura física e o professor utilizará todos os recursos disponíveis para o planejamento do curso e execução das aulas, foram significativas para a associação com a variável dependente (Expectativa quanto ao curso). Isto significa que das 
cinco variáveis apresentadas, três estão associadas positivamente e duas estão associadas negativamente, na percepção do corpo docente, à expectativa do aluno com relação ao curso.

Após a identificação das variáveis significativas na percepção dos alunos e do corpo docente para o estudo da variável dependente (Expectativa quanto ao curso), observou-se que tanto a expectativa do aluno quanto a percepção do corpo docente resultou em cinco variáveis significativas, no entanto, a percepção do professor sobre a expectativa do aluno apresentou quatro variáveis diferentes, o que evidencia a lacuna de pensamento entre as duas populações pesquisadas. Este resultado pode motivar a insatisfação do aluno, caso suas demandas não sejam concretizadas. A única variável em comum obtida entre alunos e professores trata do crescimento e desenvolvimento pessoal e profissional. Isto mostra que o desenvolvimento pessoal e profissional se apresenta como um resultado esperado pelo aluno após a conclusão do curso superior e que o professor tem conhecimento disso. A literatura confirma que o aluno espera que os processos da IES o ajudem a alcançar seus objetivos profissionais e pessoais (LETCHER \& NEVES, 2010).

Os resultados da pesquisa demonstram que as expectativas do aluno com relação ao curso estão alinhadas com os estudos de Aziz (2013), Crisp et al. (2009), Letcher \& Neves (2010) e Surman (2013). Com relação à percepção do corpo docente, ao indicar a expectativa do aluno, os resultados corroboram com os estudos evidenciados por Bitner (1990), Davies (2002), Emanuel et al (2006), Letcher \& Neves (2010), Marimuthu et al (2012) e Surman (2013). Verificou-se que o gap 1 apareceu, indicando que o professor, ao pensar na expectativa do aluno com relação ao curso, acredita que os aspectos físicos, tais como recursos em sala de aula, estrutura física e tecnologia, são significativos. No entanto, os alunos consideraram relevante a interação durante o processo da prestação do serviço e os resultados que eles alcançarão após a conclusão do curso superior.

\subsubsection{Regressões para Análise da Variável Dependente: Expectativa quanto à IES}

Para complementar a identificação do gap 1 entre o que o aluno espera da IES ao ingressar em um curso superior e o que o corpo docente acredita que o aluno espera, foram realizadas duas regressões lineares múltiplas entre as 30 variáveis independentes e a variável dependente: expectativa quanto à IES. Os resultados das expectativas dos alunos estão demonstrados nas tabelas 5 e 6 . 
Tabela 5 Modelo obtido na Regressão Linear Múltipla para os Discentes.

\begin{tabular}{|c|c|c|c|c|c|c|c|c|c|c|}
\hline \multicolumn{11}{|c|}{ Modelo Resumido } \\
\hline \multirow[b]{2}{*}{ Modelo } & \multirow[b]{2}{*}{$\mathrm{R}$} & \multirow[b]{2}{*}{$\mathrm{R}^{2}$} & \multirow[b]{2}{*}{$\begin{array}{c}\mathrm{R}^{2} \\
\text { Ajustado }\end{array}$} & \multirow{2}{*}{$\begin{array}{c}\text { Erro Padrão } \\
\text { da } \\
\text { Estimativa }\end{array}$} & \multicolumn{5}{|c|}{ Alterações Estatísticas } & \multirow[b]{2}{*}{$\begin{array}{l}\text { Durbin- } \\
\text { Watson }\end{array}$} \\
\hline & & & & & $\begin{array}{c}\text { Variação do } \\
\mathrm{R}^{2}\end{array}$ & $\begin{array}{c}\text { Alteração } \\
\text { F }\end{array}$ & $\begin{array}{c}\mathrm{ddf} \\
1\end{array}$ & ddf2 & $\begin{array}{l}\text { Alterações } \\
\text { Sig. F }\end{array}$ & \\
\hline 4 &, 504 & ,254 & ,241 & 61119 & ,018 & 5,683 & 1 & 232 & ,018 & 2,152 \\
\hline
\end{tabular}

a. Preditores: (Constante), Aulas agradáveis e interessantes, Boa estrutura física, IES com fortes ligações com o mercado de trabalho, Comunicação precisa sobre cursos, procedimentos de avaliação e processo de reclamações.

b. Variável Dependente: Expectativa quanto à IES.

Método de estimação: Stepwise

Testes de validez:

ANOVA: significativo

Teste de Aleatoriedade: Suporta a hipótese de aleatoriedade

Teste de Aderência Kolmogorov-Smirnov: Suporta hipótese de aderência a distribuição normal

Teste de Homocedasticidade: Suporta a hipótese de homocedasticidade

Fonte: Dados da Pesquisa.

Tabela 6 Coeficientes estimados da variável dependente (Expectativa quanto à IES) para os Discentes.

\begin{tabular}{|c|c|c|c|c|c|c|c|c|c|c|c|c|c|}
\hline & \multicolumn{13}{|c|}{ Coeficientes $^{\mathrm{a}}$} \\
\hline & \multirow[t]{2}{*}{ Modelo } & \multicolumn{2}{|c|}{$\begin{array}{l}\text { Coeficient } \\
\text { es não } \\
\text { padroniza } \\
\text { dos }\end{array}$} & \multirow{2}{*}{$\begin{array}{c}\text { Coeficient } \\
\text { es } \\
\text { Padroniza } \\
\text { dos }\end{array}$} & \multirow[t]{2}{*}{$\mathrm{tt}$} & \multirow{2}{*}{$\begin{array}{l}\mathrm{SSi} \\
\mathrm{g} .\end{array}$} & \multicolumn{2}{|c|}{$\begin{array}{c}95,0 \% \\
\text { Intervalo de } \\
\text { Confiança para } \\
\text { B }\end{array}$} & \multicolumn{3}{|c|}{ Correlação } & \multicolumn{2}{|c|}{$\begin{array}{l}\text { Estatística de } \\
\text { Colinearidade }\end{array}$} \\
\hline & & B & $\begin{array}{c}\text { Erro } \\
\text { Padr } \\
\text { ão }\end{array}$ & & & & $\begin{array}{c}\text { Limite } \\
\text { Inferio } \\
\mathrm{r}\end{array}$ & $\begin{array}{l}\text { Limite } \\
\text { Superi } \\
\text { or }\end{array}$ & $\begin{array}{c}\text { Orde } \\
\mathrm{m} \\
\text { Zero }\end{array}$ & $\begin{array}{l}\text { Parci } \\
\text { al }\end{array}$ & $\begin{array}{l}\text { Semipar } \\
\text { cial }\end{array}$ & $\begin{array}{c}\text { Tolerân } \\
\text { cia }\end{array}$ & VIF \\
\hline & (Constante) & \begin{tabular}{|c|}
, 93 \\
8
\end{tabular} &, 387 & & $\begin{array}{c}2,42 \\
4\end{array}$ & $\begin{array}{c}, 01 \\
6\end{array}$ & , 176 & 1,701 & & & & & \\
\hline & \begin{tabular}{|c|} 
Aulas \\
agradáveis e \\
interessante \\
$\mathrm{s}$ \\
\end{tabular} & $\begin{array}{c}, 28 \\
4\end{array}$ &, 075 & ,238 & $\begin{array}{c}3,78 \\
1\end{array}$ & $\begin{array}{c}, 00 \\
0\end{array}$ & , 136 & ,432 & ,381 & ,241 & ,214 & ,812 & $\begin{array}{c}1,23 \\
2\end{array}$ \\
\hline & \begin{tabular}{|c|} 
Boa \\
estrutura \\
física \\
\end{tabular} & $\begin{array}{c}, 17 \\
8\end{array}$ &, 059 &, 183 & $\begin{array}{c}3,00 \\
8\end{array}$ & $\begin{array}{c}, 00 \\
3\end{array}$ & ,061 & ,295 & ,317 & , 194 &, 171 & ,867 & $\begin{array}{c}1,15 \\
4\end{array}$ \\
\hline 4 & \begin{tabular}{|c|} 
IES com \\
fortes \\
ligações \\
com o \\
mercado de \\
trabalho \\
\end{tabular} & $\begin{array}{c}, 14 \\
0\end{array}$ &, 052 & , 165 & $\begin{array}{c}2,71 \\
0\end{array}$ & $\begin{array}{c}, 00 \\
7\end{array}$ & ,038 & ,241 & ,316 & , 175 & , 154 & 870 & $\begin{array}{c}1,15 \\
0\end{array}$ \\
\hline & $\begin{array}{l}\text { Comunicaç } \\
\text { ão precisa } \\
\text { sobre } \\
\text { cursos, } \\
\text { procedimen } \\
\text { tos de } \\
\text { avaliação e } \\
\text { processo de } \\
\text { reclamações }\end{array}$ & $\begin{array}{c}, 13 \\
9\end{array}$ &, 058 &, 153 & $\begin{array}{c}2,38 \\
4\end{array}$ & $\begin{array}{c}, 01 \\
8\end{array}$ & ,024 & ,255 &, 345 & , 155 & , 135 & ,778 & $\begin{array}{c}1,28 \\
5\end{array}$ \\
\hline
\end{tabular}

Fonte: Dados da Pesquisa. 
Após analisar os dados da tabela 5, verificou-se que o modelo possui um $\mathrm{R}^{2}$ ajustado de 0,241 , ou seja, $24,10 \%$ da variação da variável dependente do estudo, que trata da expectativa do aluno com relação à IES, pode ser explicada pelo modelo de regressão apresentado.

Por meio da tabela 6 , foi possível observar que as variáveis aulas agradáveis e interessantes, boa estrutura física, IES com fortes ligações com o mercado de trabalho e comunicação precisa sobre cursos, procedimentos de avaliação e processo de reclamações, foram significativas na associação com a variável dependente (Expectativa quanto à IES). Isto significa que as quatro variáveis apresentadas afetam positivamente à expectativa do aluno com relação à instituição de ensino superior.

Por outro lado, as tabelas 7 e 8 mostram os resultados obtidos junto ao corpo docente. Após analisar os dados da tabela 7 , verificou-se que o modelo possui um $\mathrm{R}^{2}$ ajustado de 0,243, ou seja, 24,3\% da variação da variável dependente (Expectativa quanto à IES), na visão do corpo docente, pode ser explicada pelo modelo de regressão apresentado.

Tabela 7 Modelo obtido na Regressão Linear Múltipla para o Corpo Docente.

\begin{tabular}{|c|c|c|c|c|c|c|c|c|c|c|}
\hline \multicolumn{10}{|c|}{ Modelo Resumido } & \multicolumn{5}{|c|}{ Alterações Estatísticas } \\
\hline \multirow{2}{*}{ Modelo } & \multirow{2}{*}{$\mathrm{R}$} & \multirow{2}{*}{$\mathrm{R}^{2}$} & $\begin{array}{c}\mathrm{R}^{2} \\
\text { Ajustado }\end{array}$ & $\begin{array}{c}\text { Erro Padrão } \\
\text { da } \\
\text { Estimativa }\end{array}$ & $\begin{array}{c}\text { Variação do } \\
\mathrm{R}^{2}\end{array}$ & $\begin{array}{c}\text { Alteração } \\
\mathrm{F}\end{array}$ & $\begin{array}{c}\mathrm{ddf} \\
1\end{array}$ & $\mathrm{ddf2}$ & $\begin{array}{c}\text { Alterações } \\
\text { Sig. F }\end{array}$ & $\begin{array}{c}\text { Durbin- } \\
\text { Watson }\end{array}$ \\
\hline 4 &, 535 &, 286 &, 243 &, 60180 &, 052 & 4,819 & 1 & 66 &, 032 & 1,989 \\
\hline
\end{tabular}

a. Preditores: (Constante), IES propicie eventos relacionados aos cursos, Realizar trabalhos voluntários em causas sociais onde a IES está inserida, Curso com mais aulas práticas do que teóricas, Aulas agradáveis e interessantes, Boa estrutura física.

b. Variável Dependente: Expectativa quanto à IES.

Método de estimação: Stepwise

Testes de validez:

ANOVA: significativo

Teste de Aleatoriedade: Suporta a hipótese de aleatoriedade

Teste de Aderência Kolmogorov-Smirnov: Suporta hipótese de aderência a distribuição normal

Teste de Homocedasticidade: Suporta a hipótese de homocedasticidade

Fonte: Dados da Pesquisa. 
Tabela 8 Coeficientes estimados da variável dependente (Expectativa quanto à IES) para o Corpo Docente.

\begin{tabular}{|c|c|c|c|c|c|c|c|c|c|c|c|c|c|}
\hline & \multicolumn{13}{|c|}{ Coeficientes $\mathrm{s}^{\mathrm{a}}$} \\
\hline & \multirow{2}{*}{ Modelo } & \multicolumn{2}{|c|}{$\begin{array}{l}\text { Coeficiente } \\
\text { s não } \\
\text { padronizado } \\
\text { s }\end{array}$} & \multirow{2}{*}{$\begin{array}{c}\text { Coeficient } \\
\text { es } \\
\begin{array}{c}\text { Padroniza } \\
\text { dos }\end{array} \\
\\
\text { Beta }\end{array}$} & \multirow{2}{*}{$\mathrm{tt}$} & \multirow{2}{*}{$\begin{array}{c}\mathrm{SSi} \\
\mathrm{g} .\end{array}$} & \multicolumn{2}{|c|}{$\begin{array}{c}95,0 \% \\
\text { Intervalo de } \\
\text { Confiança } \\
\text { para B }\end{array}$} & \multicolumn{3}{|c|}{ Correlação } & \multicolumn{2}{|c|}{$\begin{array}{l}\text { Estatística de } \\
\text { Colinearidade }\end{array}$} \\
\hline & & B & $\begin{array}{l}\text { Erro } \\
\text { Padr } \\
\text { ão }\end{array}$ & & & & $\begin{array}{l}\text { Limit } \\
\mathrm{e} \\
\text { Inferi } \\
\text { or }\end{array}$ & $\begin{array}{l}\text { Limite } \\
\text { Superi } \\
\text { or }\end{array}$ & $\begin{array}{c}\text { Orde } \\
\mathrm{m} \\
\text { Zero }\end{array}$ & $\begin{array}{c}\text { Parci } \\
\text { al }\end{array}$ & $\begin{array}{c}\text { Semipar } \\
\text { cial }\end{array}$ & $\begin{array}{l}\text { Tolerân } \\
\text { cia }\end{array}$ & VIF \\
\hline & $\begin{array}{c}\text { (Constante } \\
\text { ) }\end{array}$ & 999 & $\begin{array}{c}1,37 \\
5\end{array}$ & & ,726 & $\begin{array}{c}47 \\
0 \\
\end{array}$ & $\begin{array}{c}- \\
1,746\end{array}$ & 3,743 & & & & & \\
\hline & $\begin{array}{c}\text { IES } \\
\text { propicie } \\
\text { eventos } \\
\text { relacionad } \\
\text { os aos } \\
\text { cursos } \\
\end{array}$ & 293 & ,089 & 346 & $\begin{array}{c}3,28 \\
8\end{array}$ & $\begin{array}{c}, 00 \\
2\end{array}$ & ,115 & ,471 & ,336 & ,375 & ,342 & 975 & $\begin{array}{c}1,02 \\
6\end{array}$ \\
\hline 4 & $\begin{array}{c}\text { Realizar } \\
\text { trabalhos } \\
\text { voluntários } \\
\text { em causas } \\
\text { sociais } \\
\text { onde a IES } \\
\text { está } \\
\text { inserida } \\
\end{array}$ & ,144 & 0,59 & ,254 & $\begin{array}{c}2,42 \\
8\end{array}$ & $\begin{array}{c}, 01 \\
8\end{array}$ & ,026 & ,263 & 292 & 286 & 252 & 989 & $\begin{array}{c}1,01 \\
1\end{array}$ \\
\hline & $\begin{array}{c}\text { Aulas } \\
\text { agradáveis } \\
\text { e } \\
\text { interessant } \\
\text { es } \\
\end{array}$ & ,541 & 240 & 235 & $\begin{array}{c}2,25 \\
6\end{array}$ & $\begin{array}{c}, 02 \\
7\end{array}$ & ,062 & 1,020 & ,234 & 268 & 235 & 997 & $\begin{array}{c}1,00 \\
3\end{array}$ \\
\hline & $\begin{array}{c}\text { Boa } \\
\text { estrutura } \\
\text { física }\end{array}$ &,- 302 & 138 &,- 230 & $\begin{array}{c}2,19 \\
5\end{array}$ & $\begin{array}{c}, 03 \\
2\end{array}$ &,- 577 &,- 027 &,- 177 &,- 261 &,- 228 & 983 & $\begin{array}{c}1,01 \\
7\end{array}$ \\
\hline
\end{tabular}

Fonte: Dados da Pesquisa.

Por meio da tabela 8 , observou-se que as variáveis IES propicie eventos relacionados ao curso, realizar trabalhos voluntários em causas sociais onde a IES está inserida, aulas agradáveis e interessantes e boa estrutura física, foram significativas na associação com a variável dependente (Expectativa quanto à IES). Isto significa que das quatro variáveis apresentadas, três estão associadas positivamente e uma está associada negativamente, na percepção do corpo docente, à expectativa do aluno com relação à IES.

Após a identificação das variáveis significativas, na percepção dos alunos e do corpo docente, para o estudo da variável dependente (Expectativa quanto à IES), observou-se que tanto a expectativa do aluno quanto a percepção do corpo docente resultou em quatro variáveis significativas, no entanto, apenas uma variável convergiu, aulas interessantes e 
agradáveis, o que evidencia a lacuna entre as duas populações pesquisadas. Isto pode contribuir para a insatisfação do aluno e para a ampliação dos índices de desistência nas IES (MARIMUTHU ET AL, 2012). O aluno acredita que a prestação de serviço de ensino superior será realizada por professores competentes e, portanto, as aulas serão interessantes e agradáveis (AZIZ, 2013; CRISP ET AL, 2009). Já o corpo docente acredita que o aluno valoriza a relação de confiança que deverá ser construída entre as duas populações abordadas nesta pesquisa (APPLETON-KNAPP ET AL, 2006; DAVIES, 2002; EMANUEL ET AL, 2006; MARIMUTHU ET AL, 2012).

Os resultados da pesquisa demonstram ainda que as expectativas do aluno com relação à IES estão alinhadas com os estudos de Aziz (2013), Bitner (1990), Crisp et al. (2009), Davies (2002), Marimuthu et al (2012). Com relação à percepção do corpo docente, ao indicar a expectativa do aluno, os resultados corroboram com os estudos evidenciados por Aziz (2013), Bitner (1990), Crisp et al. (2009), Davies (2002), Martinez et al. (2007), Sander et al. (2000), Stevenson et al (1998). Novamente, verificou-se que o gap 1 apareceu, indicando que o professor, ao pensar na expectativa do aluno com relação à IES, destaca a prestação dos serviços. Já o aluno demonstra que, além da prestação do serviço, ele considera os resultados que ele alcançará após o término do curso superior.

Os resultados sugerem a necessidade de a IES conhecer e passar a atender as expectativas dos alunos. Possivelmente, essa atitude evitará futuras insatisfações, promoverá um gerenciamento mais eficaz de recursos e esforços e investirá em um relacionamento mais alinhado com as expectativas dos alunos ao longo da vida acadêmica. Neste sentido, percebeu-se a necessidade de orientar o corpo docente no que se refere às expectativas dos alunos com relação ao curso e à IES.

\section{CONCLUSÃO}

O objetivo deste estudo foi identificar o gap 1 entre as expectativas do aluno ingressante no ensino superior e o que o corpo docente acredita que o aluno espera de um curso e de uma instituição de ensino superior.

Os resultados evidenciaram a diferença de pensamento entre discentes e corpo docente. Esse resultado sugere a existência da lacuna de conhecimento entre alunos e professores relacionada às expectativas dos alunos ingressantes em uma IES. A discrepância encontrada na avaliação entre discentes e docentes indica que o corpo docente não possui 
informações precisas quanto aos aspectos mais valorizados pelos alunos, havendo a necessidade da IES e do seu corpo docente estarem atentos para as expectativas verdadeiramente importantes para os alunos e, assim, empregar recursos de forma mais assertiva. (GREBENNIKOV ET AL, 2013; LONG ET AL, 1999; SARRICO ET AL, 2014).

Além disso, as variáveis identificadas nas regressões, relacionadas às expectativas dos alunos quanto ao Curso e à IES, foram substancialmente diferentes entre os discentes e o corpo docente. Os resultados parecem indicar que o corpo docente acha que o aluno espera aspectos relacionados à estrutura física, tecnologia, processos internos e recursos necessários na prestação de serviço de ensino. Enquanto isso, o aluno espera que todos esses aspectos acadêmicos e não acadêmicos sejam um meio para chegar até o seu objetivo central, que é uma colocação no mercado de trabalho e sua ascensão na carreira profissional e na vida pessoal (DAVIES, 2002; LONG ET AL, 2003).

Por meio desses resultados, a pesquisa contribui para a compreensão das expectativas de alunos ingressantes no ensino superior e compara essas expectativas com a visão do principal prestador do serviço educacional, o professor. Dessa forma, este estudo pretendeu contribuir com a literatura, tendo em vista que as percepções relacionadas às mudanças no contexto educacional apontam a necessidade de realizar mais estudos na área de qualidade das IES, com o objetivo de atualizá-la para o futuro (GREBENNIKOV ET AL, 2013; MARIMUTHU ET AL, 2012; SARRICO ET AL, 2014).

As IES enfrentam uma forte concorrência, não apenas com outras IES, mas também com novos modelos de ensino, como o ensino a distância. Diante deste cenário, a pesquisa também contribui com as IES na tarefa de atrair e reter alunos. Além disso, aprofunda o modelo dos 5 Gaps da Qualidade, investigando o Gap 1 entre corpo docente e os discentes.

Apesar das contribuições, esse estudo acadêmico possui limitações que precisam ser mencionadas. É necessário destacar que esta pesquisa contemplou apenas uma instituição de ensino superior. Para futuros estudos, é importante replicar a mesma pesquisa em outras IES, no intuito de avaliar as expectativas dos discentes e as diferenças de pensamento entre os alunos e o corpo docente.

Também recomenda-se a realização de um estudo longitudinal, visto que o referencial teórico evidenciou que as expectativas mudam ao longo do tempo, havendo a necessidade de acompanhamento e atualização constantes em função do dinamismo das relações comerciais. 
Além disso, podem existir expectativas de alunos que não foram mencionadas neste estudo e que sejam consideradas relevantes pelos próprios alunos.

Como sugestão para novas pesquisas, sugere-se ainda a realização do estudo com outros stakeholders envolvidos na relação com os alunos, como os principais gestores da IES e o pessoal não acadêmico.

\section{REFERÊNCIAS}

Abdullah, F. The development of HEdPERF: A new measuring instrument of service quality for the higher education sector. International Journal of Consumer Studies, 30(6), 569$581,2006$.

Akareem, H. S.; Hossain, S. S. Perception of education quality in private universities of Bangladesh: A study from students' perspective. Journal of Marketing for Higher Education, 22(1), 11-33, 2012.

Al-Fattal, A.; Ayoubi, R. Student needs and motives when attending a university: Exploring the Syrian case. Journal of Marketing for Higher Education, 23(2), 204-225, 2013.

Appleton-Knapp, S. L.; Krentler, K. A. Measuring student expectations and their effects on satisfaction: The importance of managing student expectations. Journal of Marketing Education, 28(3), 254-264, 2006.

Bitner, M. J. Evaluating service encounters: The effects of physical surroundings and employee responses. The Journal of Marketing, 54, 69-82, 1990.

CRISP, G.; PALMER, E.; TURNBULL, D.; NETTELBECK, T.; WARD, L.; LECOUTEUR, A.; SARRIS, A; STRETAN, P.; SCHNEIDER, L. First year student expectations: Results from a university-wide student survey. Journal of University Teaching \& Learning Practice, 6(1), 2009.

DAVIES, S. Responding to student expectations. Marketing in higher education: Matching promises and reality to expectations. Paris: OECD, 2002.

DUZEVIC, I. A conceptual framework for analysing the impact of influences on student engagement and learning. Tertiary Education and Management, 21(1), 66-79, 2015.

EMANUEL, R.; ADAMS, J. N. Assessing college student perceptions of instructor customer service via the Quality of Instructor Service to Students (QISS) Questionnaire. Assessment \& Evaluation in Higher Education, 31(5), 535-549, 2006.

FAGANEL, A. Quality perception gap inside the higher education institution. International Journal of Academic Research, 2(1), 213-215, 2010.

GRAY, C., SWAIN, J.; RODWAY-DYER. S. Student voice and engagement: connecting through partnership. Tertiary Education and Management, 20(1), 57-71, 2014. 
GREBENNIKOV, L.; SHAH, M. Monitoring Trends in Student Satisfaction. Tertiary Education and Management, 19(4), 301-322, 2013.

GRUBER, T. Academic sell-out: How an obsession with metrics and rankings is damaging academia. Journal of Marketing for Higher Education, 24(2), 165-177, 2014.

HAIR JR., J. F.; CELSI, M. W; MONEY, A. H.; SAMOUEL, P.; PAGE, M. J. Essentials of Business Research Methods. New York: Third Edition, 2011.

HEADAR, M. M.; ELAREF, N.; YACOUT, O. M. Antecedents and Consequences of Student Satisfaction with e-Learning: The Case of Private Universities in Egypt. Journal of Marketing for Higher Education, 23(2), 226-257, 2013.

HILL, F. M. Managing service quality in higher education: The role of the student as primary consumer. Quality Assurance in Education, 3(3), 10-21, 1995.

JILLAPALLI, R. K; JILLAPALLI, R. Do professors have customer-based brand equity? Journal of Marketing for Higher Education, 24(1), 22-40, 2014.

KRIEG, D. B. High Expectations for Higher Education? Perceptions of College and Experiences of Stress Prior to and Through the College Career. College Student Journal, 47(4), 635-643, 2013.

LONG, P.; TRICKER, T.; RANGECROFT, M. Measuring aspects of student satisfaction with course provision. Probing The Boundaries of Higher Education, 5, 105-109, 2003.

LONG, P.; TRICKER, T.; RANGECROFT, M.; GILROY, P. Measuring the satisfaction gap: Education in the market-place. Total Quality Management, 10(4\&5), 772-778, 1999.

MAINARDES, E.; ALVES, H.; RAPOSO, M. Portuguese Public University Student Satisfaction: A stakeholder theory-based approach. Tertiary Education and Management, 19(4), 353-372, 2013.

MAINARDES, E.; ALVES, H.; RAPOSO, M. Using expectations and satisfaction to measure the frontiers of efficiency in public universities. Tertiary Education and Management, 20(4), 339-353, 2014.

MAINARDES, E.; RAPOSO, M.; ALVES, H. Public University Students' Expectations: An Empirical Study Based on the Stakeholders Theory. Transylvanian Review of Administrative Sciences, 35, 173-196, 2012.

MARIMUTHU, M.; ISMAIL, I. Service Quality in Higher Education: Comparing the Perceptions of Stakeholders. NINTH AIMS INTERNATIONAL CONFERENCE ON MANAGEMENT, 515-523(1-4), 2012. 
MARTINEZ, M. D. C. P.; BERBÉN, A. B. G.; ARIAS, J. D. L. F.; JUSTICIA, F. J. El estudio de las expectativas en la universidad: Análisis de trabajos empíricos y futuras líneas de investigación. Revista Electrónica de Investigación Educativa, 9(1), 1-16, 2007.

MARTÍNEZ, T. L.; TOLEDO, L. D. What do graduates think? An analysis of intention to repeat the same studies and university. Journal of Marketing for Higher Education, 23(1), 62-89, 2013.

MAVONDO, F. T.; TSARENKO, Y.; GABBOTT, M. International and local student satisfaction: Resources and capabilities perspective. Journal of Marketing for Higher Education, 14(1), 41-60, 2004.

MIZIKACI, F. A systems approach to program evaluation model for quality in higher education. Quality Assurance in Education, 14(1), 37-53, 2006.

PARAHOO, S. K.; HARVEY, H. L.; TAMIM, R. M. Factors influencing student satisfaction in universities in the Gulf region: Does gender of students matter? Journal of Marketing for Higher Education, 23(2), 135-154, 2013.

PARASURAMAN, A.; ZEITHAML, V. A.; BERRY, L. L. A conceptual model of service quality and its implications for future research. The Journal of Marketing, 41-50, 1985.

RAVINDRAN, S. D.; KALPANA, M. Student's Expectation, Perception and Satisfaction towards the Management Educational Institutions. Procedia Economics and Finance, 2, 401-410, 2012.

SAMPAIO, C. H.; PERIN, M. G.; SIMÕES, C.; KLEINOWISKI, H. Students' trust, value and loyalty: evidence from higher education in Brazil. Journal of Marketing for Higher Education, 22(1), 83-100, 2012.

SANDER, P.; STEVENSON, K.; KING, M.; COATES. D. University students' expectations of teaching. Studies in Higher Education, 25(3), 309-323, 2000.

SARRICO, C. S.; ROSA, M. J. Student satisfaction with Portuguese higher education institutions: the view of different types of students. Tertiary Education and Management, 20(2), 165-178, 2014.

STEVENSON, K.; SANDER, P. How do Open University Students Expect to be Taught at Tutorials? Open Learning, 13(2), 42-46, 1998.

SUARMAN; AZIZ, Z.; YASIN, R. M. The Quality of Teaching and Learning towards the Satisfaction among the University Students. Asian Social Science, 9(12), 252-260, 2013.

WARDLEY, L. J.; BÉLANGER, C. H.; LEONARD, V. M. Institutional commitment of traditional and non-traditional-aged students: A potential brand measurement? Journal of Marketing for Higher Education, 23(1), 90-112, 2013. 